This item was submitted to Loughborough's Research Repository by the author.

Items in Figshare are protected by copyright, with all rights reserved, unless otherwise indicated.

\title{
The role of frames and cultural toolkits in establishing new connections for social media innovation
}

PLEASE CITE THE PUBLISHED VERSION

https://doi.org/10.1016/j.techfore.2017.07.026

PUBLISHER

(C) Elsevier

VERSION

AM (Accepted Manuscript)

\section{PUBLISHER STATEMENT}

This work is made available according to the conditions of the Creative Commons Attribution-NonCommercialNoDerivatives 4.0 International (CC BY-NC-ND 4.0) licence. Full details of this licence are available at: https://creativecommons.org/licenses/by-nc-nd/4.0/

\section{LICENCE}

CC BY-NC-ND 4.0

\section{REPOSITORY RECORD}

Richey, Michelle, and Ravishankar Mayasandra-Nagaraja. 2017. "The Role of Frames and Cultural Toolkits in Establishing New Connections for Social Media Innovation”. figshare. https://hdl.handle.net/2134/26055. 
1 The role of frames and cultural toolkits in establishing new connections

2 for social media innovation

4 ABSTRACT

5 It has been suggested that social media foster innovative outcomes by

6 facilitating communication with a vast network of new connections. In this paper

7 we argue that forming new social connections on social media is a crucial first

8 step in the innovation process that is not straightforward to achieve. We report

9 on the findings of a qualitative study of 31 owner-managers in the UK who were

10 attempting to make new connections in order to inspire innovation in their firms.

11 The findings suggest that a lack of available social cues on social media creates

12 a sense of uncertainty that can stifle the innovation process. In our case, the

13 respondents addressed these difficulties by using frames as proxies for missing

14 social stimuli. We argue that such framings guide the selection of well-

15 established cultural tools needed to turn mental maps into action. A key

16 implication of our findings is that social media is not necessarily an equitable

17 space for innovation since the process still relies upon established networks

18 and styles of behaviour, which are not readily accessible to all.

20 KEYWORDS: Social media; innovation; new connections; frames; cultural 21 toolkits. 
36 The higher the number of social contacts an individual maintains, the more

37 likely she is to generate new ideas (Bjork \& Magnusson, 2009) by discovering, 38 combining and expanding upon new information. This is one way that social 39 media promises to bolster innovation. Social media facilitate the expansion of 40 an individual's social network to a previously unimaginable scale (Kane et al., 41 2014). By extension, individuals who enlarge their social networks using social media are exposed to new ideas and information that were previously inaccessible (Treem \& Leonardi, 2012; Leonardi, 2014). To make the most of their social media accounts individuals attempt to expand their networks to include as many new connections as possible (Kane et al., 2014). As people associate with other social media users they can find themselves engaging with different viewpoints, experiences and expertise (Kane et al., 2014). When these new connections bring together previously separate information resources opportunities for the discovery, recombination and expansion of ideas are believed to increase significantly (Mount \& Martinez, 2014; Dahlander \& 51 Piezunka, 2014).

There are several recent anecdotal illustrations showing how new connections on social media can fuel innovation. For example, Dr Jeffrey Davis, Head of the Human Health and Performance Directorate for NASA realized in the face of budget cuts that he would need to access ideas and information beyond what was available internally (Knowledge@Wharton, 2013). He used several online platforms to make new connections, which provided many unexpected and helpful insights. Individuals from diverse backgrounds suggested innovative ideas that were taken up by NASA, such as the use of flexible graphite as a solution for preserving food and a new algorithm for predicting solar flares. Illustrations such as these highlight the fundamental role that new connections play in providing novel information that fuels the innovation process.

Recent studies have suggested that social media can play an increasingly prominent role in such open innovation efforts of firms (Mount \& Martinez, 2014; West \& Bogers, 2013). Here, the term open innovation refers to the opening up of the innovation process to include ideas that are generated externally (West 
$69 \&$ Bogers, 2013). Social media have dramatically improved the ability of firms 70 to seek external suggestions, ideas and opinions by forging new connections 71 (Mount \& Martinez, 2014; Dahlander \& Piezunka, 2014; Leonardi, 2014). The 72 material features of the platforms enable a markedly different way of 73 communicating (Treem \& Leonardi, 2012; Leonardi, 2014) leading to claims of 74 a new wave of open innovation for firms (Mount \& Martinez, 2014). Interaction 75 with a diverse array of external connections can provide quick, cheap access 76 to a rich source of ideas, expertise and opinions (Mount \& Martinez, 2014; Leonardi, 2014). For this reason social media platforms have been thought to provide significant advantages in situations where resources to innovate can be scarce, such as in small and medium sized firms (Harris et al., 2012). We use the term social media innovation hereafter to refer to novel improvements in products or processes that originate from social media connections. We argue that social media innovation is not straightforward to achieve. Dahlander and Piezunka (2014) suggest that studies of open innovation often underplay or overlook the challenges of engaging with external connections. The features of social media platforms can complicate the establishment of new connections (Richey et al., 2016). The vast scale of interactions taking place on social media require users to frequently scan the environment in order to make sense of the volume of information being produced (Leonardi, 2014). Further, because new acquaintances are not physically co-present during social media encounters individuals can become uncertain about how to communicate effectively (Richey et al., 2016). Social media communication strips away traditionally available social cues (Richey et al., 2016; French \& Read, 2013) making it more challenging to establish mutual understanding. Where a rich array of social cues are available, they support the construction of new relationships and effective communication (Rettie, 2009; Goffman, 1959). The innovation process relies on interaction and communication at every stage (Mount \& Martinez, 2014), but there has been little focus on the important preliminary step of establishing new social connections for initiating social media innovation. Although social media appear to offer unlimited access to new connections there is currently scant understanding about how these relationships are initiated and developed. 
Novel Information

\section{Innovation}

103

104

105

106

107

108

109

110

111

112

113

114

115

116

117

118

119

120

121

122

123

124

125

Figure 1: Overview of the social media innovation process

We use Figure 1 to locate the focus of our study in the social media innovation process. This paper focuses specifically on the first box in the figure, which refers to the potential of social media for initiating new social connections that can provide access to novel information and ideas. This paper shows how individuals attempting to make new social media connections are challenged by the lack of available social cues and how they use frames (Goffman, 1974) and cultural tools (Swidler, 1986) to establish a foundation for social media innovation. We present findings from a qualitative study of 31 UK-based ownermanagers, who were attempting to access novel insights by extending their social media networks. We offer two major contributions based on our analysis of their accounts. First, we elaborate upon how individuals respond to the uncertainty associated with making new social media connections by experimenting with different frames (Goffman, 1974) which serve as a proxy for conventional social cues. In doing this we contribute to the innovation literature by unpacking the micro-processes that underpin the fundamental step of initiating new social connections on social media. Second, we show that although the innovation process is traditionally associated with new ways of thinking and acting, individuals are better able to navigate the early stages of social media innovation if they draw upon an already existing cultural toolkit 125 (Swidler, 1986) of well-established competencies. We develop these 
126 arguments by drawing on the sociological foundations of new relationships

127 (Goffman, 1959; Swidler, 1986).

128

\section{LITERATURE REVIEW}

130

131 Face-to-face relationships and the availability of cues.

133 For cooperation and intelligible communication to occur between new

134 acquaintances there must first be some level of shared understanding 135 (Goffman, 1981). Co-communicants begin to establish communal 136 understandings in the earliest moments of interaction by making use of 137 commonly understood social cues (Goffman, 1959, 1981). Social cues can 138 include that which is subjectively described, such as tone of voice (Goffman, 139 1959), gesture (Cornelissen et al., 2014), common stories (Beech et al., 2009) 140 and humour (Robert \& Wilbanks, 2012); and that which is objectively described 141 such as architectural lay out, logos, artwork and dress code (Schein, 1991). 142 These cues work together to communicate an unambiguous and consistent 143 meaning to those involved in an encounter (Goffman, 1959). In face-to-face 144 settings social cues are clearly accessible to everyone involved as all share the 145 same space and time. This enables them to "share a joint focus of attention, 146 perceive that they do so, and perceive this perceiving" (Goffman, 1983: 3). As 147 individuals draw on available cues they are able to frame (Goffman, 1974; 148 Werner \& Cornelissen, 2014) their situation in specific ways. Frames (Goffman, 149 1974) are the schemata of interpretation that guide an individual's thinking and 150 action in relation to a phenomenon. Individuals may frame the same situation 151 differently depending on their various social realities and mental models 152 (Leonardi, 2011). For example, within the same firm, some people may frame 153 social media as a threat whilst others frame it as an opportunity (Koch et al., 154 2013).

156 Social media relationships and interactions 
158 The electronically mediated nature of social media platforms creates a

159 markedly different context for establishing new social connections. Social 160 media users do not necessarily share the same space or time making their 161 communications largely asynchronous (Walther, 2007). Communication is 162 achieved via social media posts composed of textual and multimedia content 163 (Kaplan \& Haenlein, 2010). Posts make otherwise fleeting communications 164 visible (Leonardi, 2014), not only to those interacting, but to third parties as well 165 (Kane et al., 2014; Treem \& Leonardi, 2012). Furthermore, social media also 166 capture information that was previously invisible, such as an individual's 167 network of contacts (Kane et al., 2014) and his/her knowledge and expertise 168 (Leonardi, 2014). As social media users communicating with posts are not in 169 each other's physical presence some of the subtleties of face-to-face 170 communication can be lost (French \& Read, 2013). Where social cues are 171 unavailable to support communication, miscommunications and mistakes can 172 occur (Richey et al., 2016) challenging understanding and damaging 173 relationships.

175 Another fundamental social shift with social media has been its facilitation of 176 many-to-many communications (Kaplan \& Haenlein, 2010). Instead of sharing 177 a single focus of attention, as is the norm during face-to-face interaction 178 (Goffman, 1983), users are part of an on-going knowledge conversation in 179 which there are potentially unlimited contributors and posts (Kane et al. 2014). 180 Under these circumstances the established roles of seeing, listening and 181 speaking are significantly challenged. Users looking for insights and ideas in 182 such a "conversation" are required to be logged in to their accounts frequently, 183 to keep up with new developments (Leonardi, 2014). Social media platform 184 developers have offered technological solutions to the human difficulties of 185 participating on this massive scale. For example, social media aggregators 186 scan platforms for the use of keywords and alert users if there is a conversation 187 that they need to check. Although these technical tools notify individuals that 188 specific keywords are being used, they do not always assist users to make new 189 connections on social media (Kane et al., 2014; Michelidou et al., 2011). There 190 still remains the more fundamental problem of making new connections in the 191 absence of conventional social cues. 
193 Frames and cultural toolkits

195 In line with the preceding review, social media can be understood as a 196 dramatically different context for making new connections and sharing novel 197 information. The paucity of social cues and demands of many-to-many 198 communication present significant challenges for those trying to initiate any 199 form of innovation through social media. According to sociologist Ann Swidler 200 (1986), encounters with an unfamiliar situation prompts individuals to assess 201 how well equipped they are to cope with the new context, understand the 202 communications of others, and to be understood (Swidler, 1986). This process

203 begins as the uncertainty related to a new situation stimulates the selection of 204 a frame (Goffman, 1974; Ravishankar, 2015). Frames provide a mechanism for 205 interpreting an unfamiliar context (in this case, social media) but must be 206 accompanied by action if it has to lead to innovation.

Swidler (1986) introduces the metaphor of a cultural 'toolkit' to illuminate the types of resources that are brought into play following framings. The toolkit is comprised of the skills, habits and styles, available at a broader societal level,

211 but practiced and brought to bear at an individual level, as people interact and 212 address challenges. Cultural tools are conceptualized as existing separately 213 but are drawn together in different assemblages for use in a wide variety of 214 situations (Swidler, 1986). Indeed, one cultural tool may be reused in a number 215 of different circumstances, while another may be left mostly dormant. Taken 216 together, frames and tools comprise the strategies of action used to deal with 217 uncertain circumstances. Thus, the cultural toolkit framework (Swidler, 1986) 218 provides a useful vocabulary to explore the extent to which the challenges of 219 new social situations in general and social media connections in particular may 220 be addressed by a conscious and purposeful drawing together of knowledge, 221 habits, skills, styles and other culturally constituted capacities. The framework 222 underscores the agency of individuals proactively combining and recombining 223 their competencies in order to cope with new situations. 
227 Innovation scholars have suggested that well-established and intimate social 228 settings characterized by effective social norms (Coleman, 1988, 1990) support 229 the innovation process by enabling the value of novel information to be 230 recognized and realized (Rost, 2011). At the same time, individuals also find 231 utility in looking beyond their close relationships, to their less well known

232 acquaintances and new connections for novel information (Dahlander \& 233 Piezunka, 2014). Social media offers users the opportunity to traverse vast 234 networks of new connections (Kane et al., 2014) developing their meta235 knowledge (Leonardi, 2014) about what others are interested in, who they know 236 and what they know. This information can be observed at an individual level, or 237 can be aggregated together, providing an overview of the mood of a population 238 (Cogburn \& Espinoza-Vasquez, 2011) or the preferences of a group of 239 consumers (Mount \& Martinez, 2014).

241 However, as noted earlier social media offers a comparatively sparse context 242 for the establishment of new connections due to the paucity of available social 243 cues (Richey et al., 2016). When individuals use social media to make new 244 connections within established boundaries (i.e. within the same organization) 245 they are able to fill in some of the perceptual gaps associated with social media 246 by using other shared referents as heuristic guides (Treem \& Leonardi, 2012; 247 Huang et al., 2013). This enables them to maintain a sense of social context 248 that aids information sharing (Huang et al., 2013). On the other hand, when 249 users are attempting to communicate and share ideas with an entirely new 250 contact there are often no shared referents available. The social media and 251 innovation literatures tend to overlook or underplay these challenges 252 (Dahlander \& Piezunka, 2014; Richey et al., 2016) resulting in a scant 253 understanding of how the new connections supporting social media innovation 254 are achieved. In the next empirical sections of the paper, we describe and 255 analyse how individuals use specific frames (Goffman, 1974) and cultural tools 256 (Swidler, 1986) to overcome the challenges of establishing new connections for 257 social media innovation. 
261 Our aim was to gather new insights into how individuals were using social 262 media to establish new connections with an ultimate aim to foster innovation.

263 Our methodology was underpinned by an interpretivist philosophy (Walsham, 264 1993; Mayasandra et al., 2006) in which human action and interaction 265 constitutes social realities (Ravishankar, 2013). In line with this view, we 266 employed qualitative methods that enabled us to gather data about the lived 267 experiences of individuals (Ravishankar et al., 2010) attempting to initiate social 268 media innovation.

270 We gathered data from the membership of two UK based, government affiliated 271 support agencies that were providing social media seminars. We assumed that 272 the membership of these support agencies represented a 'purposive sample' 273 (Padgett, 1998) that would be experiencing varying degrees of success on 274 social media, and would have been exposed to similar opportunities and 275 resources by virtue of their membership. We contacted the local offices of both 276 agencies, offering consultancy services in exchange for participation in the 277 study. A formal note detailing the offer was circulated by email among local 278 members of both organizations. The firms that took part in the interviews were 279 representative of the variety of industries that made up the wider membership 280 of the support agencies (see Table 1).

\begin{tabular}{|llll|}
$\begin{array}{l}\text { Organizational } \\
\text { Identifier }\end{array}$ & Industry Sector & $\begin{array}{l}\text { Number of } \\
\text { Employees }\end{array}$ & $\begin{array}{l}\text { Number of } \\
\text { Interviewees }\end{array}$ \\
\hline Org 1 & Charity & 10 & 1 \\
\hline Org 2 & Charity & 10 & 1 \\
\hline Org 3 & Fashion & 3 & 2 \\
\hline Org 4 & Fashion & 2 & 1 \\
\hline Org 5 & Food and Drink & 10 & 1 \\
\hline Org 6 & Food and Drink & 3 & 1 \\
\hline Org 7 & Commodity e-Retailer & 3 & 1 \\
& & & \\
\hline Org 8 & Design Consultancy & 3 & 2 \\
\hline Org 9 & Internet Security & 10 & 1 \\
\hline Org 10 & Media Production & 9 & 1 \\
\hline Org 11 & Public Relations & 2 & 1 \\
\hline Org 12 & Arts and Crafts & 5 & 2 \\
\hline
\end{tabular}




\begin{tabular}{|llll|}
\hline Org 13 & Corporate Finance & 3 & 1 \\
\hline Org 14 & Charity & 6 & 3 \\
\hline Org 15 & Chemical Engineering & 3 & 1 \\
\hline Org 16 & Domestic Installations & 3 & 1 \\
\hline Org 17 & Electrical Engineering & 4 & 2 \\
\hline Org 18 & Engineering & 2 & 2 \\
\hline Org 19 & Engineering & 3 & 1 \\
\hline Org 20 & Engineering & 8 & 1 \\
\hline Org 21 & Film Production & 5 & 2 \\
\hline Org 22 & Food and Drink & 9 & 1 \\
\hline Org 23 & Food and Drink & 5 & 2 \\
\hline Org 24 & Health and Beauty & 10 & 1 \\
\hline Org 25 & Health and Fitness & 7 & 1 \\
\hline Org 26 & Accountancy & 9 & 2 \\
\hline Org 27 & Performing Arts & 2 & 2 \\
\hline Org 28 & Property & 7 & 1 \\
\hline Org 29 & Management & & \\
\hline Org 30 & Devearch and & 3 & 1 \\
\hline Org 31 & Telecomment & 10 & 1 \\
\hline
\end{tabular}

Table 1: Participating organizations

284 All the respondents were using the four most popular, free, publically available

285 social media platforms; Facebook, Twitter, Linkedln and YouTube. They were 286 using social media in order to make new connections, which they hoped would 287 lead to some form of innovation. The main source of data was open-ended 288 interviews. The interviews included questions about how and why the firms 289 were using social media to accomplish innovation. Table 2 is an illustration of 290 some of the innovative outcomes expected by the respondents.

\begin{tabular}{|c|c|c|c|}
\hline $\begin{array}{l}\text { Organizational } \\
\text { identifier }\end{array}$ & Industry & $\begin{array}{l}\text { Illustrative } \\
\text { quote }\end{array}$ & $\begin{array}{l}\text { Innovation } \\
\text { expectations }\end{array}$ \\
\hline Org 21 & Film production & $\begin{array}{l}\text { "We are constantly } \\
\text { looking for ideas that } \\
\text { will spark a new project. } \\
\text { That impetus can come } \\
\text { from anything, so } \\
\text { seeing what people are } \\
\text { sharing on social media } \\
\text { is very useful" }\end{array}$ & Idea generation \\
\hline Org 28 & $\begin{array}{l}\text { Property } \\
\text { Management }\end{array}$ & $\begin{array}{l}\text { "I look at what other } \\
\text { managers are doing on } \\
\text { social media and }\end{array}$ & $\begin{array}{l}\text { Recombinant } \\
\text { innovation }\end{array}$ \\
\hline
\end{tabular}




\begin{tabular}{|c|c|c|c|}
\hline & & $\begin{array}{l}\text { sometimes l'll hash } \\
\text { those things together." }\end{array}$ & \\
\hline Org 12 & Arts \& Crafts & $\begin{array}{l}\text { "I love the idea of a } \\
\text { mash-up, taking ideas } \\
\text { from really different } \\
\text { places to create new } \\
\text { designs. Social media } \\
\text { is literally global so } \\
\text { those sources of } \\
\text { inspiration can be so } \\
\text { different!" }\end{array}$ & $\begin{array}{l}\text { Recombinant } \\
\text { innovation }\end{array}$ \\
\hline Org 30 & Telecomms & $\begin{array}{l}\text { "I enjoy getting in to it } \\
\text { with other techie types } \\
\text { about how to make stuff } \\
\text { better. I hope that one } \\
\text { day something } \\
\text { innovative will come of } \\
\text { it!" }\end{array}$ & $\begin{array}{l}\text { Innovative } \\
\text { collaborations }\end{array}$ \\
\hline Org 6 & Food \& Drink & $\begin{array}{l}\text { "I've developed a great } \\
\text { social media } \\
\text { community that adds so } \\
\text { much value to my } \\
\text { business. Always } \\
\text { someone with a new } \\
\text { idea or perspective." }\end{array}$ & Idea generation \\
\hline
\end{tabular}

Table 2: Examples of anticipated social media innovation outcomes

295 The main group of respondents were the owner-managers, but other 296 employees involved in social media implementation were also interviewed where available. The interviews lasted between 30 and 90 minutes. They were recorded and transcribed with the permission of the respondents.

The data was analysed (around 500 pages of interview transcripts) in multiple rounds of coding, summarized in Table 3. Initially, each interview transcript was read and summarized in order to establish the key themes underpinning them. The respondents shared accounts about (a) how they developed an understanding of social media use and (b) how they engaged in new interactions on social media. The data was organized according to these two meta-themes and a first round of coding was undertaken in which each coding 
unit was a complete sentence or series of complete sentences that constituted a single semantic unit. During the first round of coding, interpretive codes were assigned to the data. Once this process was complete any codes that reflected the same idea were combined until a stable set of interpretive codes had been

311 established.

The respondents shared many examples about how communication on social

314 media was distinctly different from their face-to-face encounters with new 315 acquaintances. They found it difficult to establish a dialogue on social media 316 because the people they directed their posts to did not always respond 317 immediately, or at all (conversation). They felt that this was in part because they 318 were not in the physical presence of those they were contacting,

\begin{tabular}{|c|c|c|}
\hline Interpretive codes & Abstract categories & $\begin{array}{l}\text { Associated } \\
\text { theoretical } \\
\text { concepts }\end{array}$ \\
\hline $\begin{array}{l}\text { Communicating } \\
\text { - } \text { Conversation } \\
\text { - Seeing } \\
\text { - Listening } \\
\text { - Relationships }\end{array}$ & $\begin{array}{l}\text { CHALLENGES } \\
\text { CREATING } \\
\text { UNCERTAINTY }\end{array}$ & $\begin{array}{l}\text { The nature of } \\
\text { social encounters } \\
\text { (Goffman, 1959, } \\
\text { 1979) }\end{array}$ \\
\hline $\begin{array}{l}\text { Sense-making tools } \\
\text { - } \quad \text { Metaphors } \\
\text { - } \quad \text { Ideas and beliefs }\end{array}$ & & \\
\hline $\begin{array}{l}\text { Practical tools } \\
\text { - Observation and } \\
\text { imitation } \\
\text { - Leverage } \\
\text { connections } \\
\text { - Social feedback }\end{array}$ & $\begin{array}{l}\text { ADDRESSING } \\
\text { CHALLENGES }\end{array}$ & $\begin{array}{l}\text { Cultural toolkits } \\
\text { (Swidler, 1986) }\end{array}$ \\
\hline
\end{tabular}

Table 3: Summary of the coding process

321 therefore eye contact and a shared focus of attention could not be established 322 (seeing). They found that it was normal on social media for users to split their 323 attention and dip in and out of different conversations. Thus, they never felt that 324 they had anyone's full attention. They also found it difficult to keep up with and 
325 be part of the larger conversations going on, because of the scale involved 326 (listening). They found that during the fleeting interactions they were part of it 327 was difficult to build a sense of rapport or trust in the same way that they might 328 do during a face-to-face meeting (relationships).

330 Since their usual means of communicating was less effective the respondents 331 were uncertain about how to make new connections on social media. In the 332 wake of this uncertainty they framed social media using a range of metaphors, 333 ideas and beliefs that enabled them to understand, approach and come to 334 terms with it. In turning the frames into action the respondents drew on 335 combinations of practical tools. These included observation and imitation of 336 other social media users' behaviour, leveraging connections they had with 337 larger organisations and collecting informal social feedback regarding the posts 338 they were making.

340 In the analysis that follows, we draw upon Goffman's work on frames and the 341 nature of social encounters $(1959,1979)$ and Swidler's (1986) cultural toolkit 342 framework to interpret respondents' accounts. Using Goffman's vocabulary we 343 highlight how the respondents became uncertain during their social media use. 344 Their uncertainty prompted them to draw upon three different social media 345 frames (Goffman, 1983) which are considered in detail in the analysis section. 346 We use Swidler's (1986) cultural toolkit framework to show how respondents 347 turned frames into strategies of action using a variety of cultural tools. The 348 theoretical and practical implications of this pattern of behaviour are expounded 349 in the discussion section.

\section{ANALYSIS}

All the respondents were interested in using social media platforms to foster innovation. They were particularly keen to initiate conversations that could lead to the discovery, recombination and expansion of new ideas. They hoped that social media would start the process by providing a simple, unobtrusive means 
Social media should be a more natural way of linking to new people, less forced than Googling somebody and trying to make a completely unsolicited approach. It facilitates new conversations. It's then about applying that, furthering it and making good, hopefully generating some opportunities on both sides. (Owner manager, design agency, Org 8).

The respondents expected social media to 'facilitate' the type of interactions they typically expected when meeting a new person. Those initial, 'getting to know' you conversations could then potentially be taken further and become a catalyst for innovation. The respondents had all initially been convinced that social media connections could develop in this way. As a result they hoped to increase their social media connections to include as many new people as possible.

However, as they began using social media to reach out and initiate contact they ran into significant difficulties. Many of these related to the perceptual gaps created by social media. Not being in the physical presence of other social media users, it was difficult to understand who they were communicating with. They struggled to know what level they should pitch their conversation at, what the other person was interested in and whether it was relevant to have a conversation at all. They tried a number of different tactics, such as initiating interest groups and responding to hash tags on popular subjects. Still, most of them were unable to initiate conversations that could lead to some form of innovation. When they reflected upon their experiences, they felt that in comparison to building relationships in face-to-face settings social media exchanges did not include enough social cues to enable them to develop a sense of who they were communicating with.

If you're not out there on social media you are potentially missing out on new opportunities, but I think there are other stronger ways of networking and building relationships. We have to build close personal relationships with new partners; they trust us implicitly. They want us to think like one of them. Do social media allow that depth of interaction? It seems to me that it's very difficult to have a genuine interaction on there when you 
can't get a sense of who you're dealing with. (Founder, research and

Respondents referred to the absence of the other party as a major barrier, particularly when a relationship was first initiated on a social media platform. They talked about feeling less able to use their intuition about their new connections if they couldn't see and interact with them in person. Many respondents were frustrated that social media inhibited their ability to interact as they would in a normal face-to-face setting. They felt that this problem limited the opportunities for finding new innovation partners on social media.

403

We haven't had much of a response so far and we want to talk about what the rules of engagement are - how do you start a conversation on social media? How do you get people interested? How do they notice you? It's a different ball game and one that I can't seem to figure out.

Their perception that there were different 'rules of engagement' that they did not grasp created a sense of uncertainty about how and why to use social media. They were uncertain about how to replicate in a social media setting the social conventions they normally followed. In managing this uncertainty respondents drew on three different, but easily accessible frames of reference.

\section{Framing social media}

The respondents framed their efforts on social media in three ways by using metaphors that acted as their interpretive schemata. These three initial framings guided their subsequent strategies of action, influencing the types of

421 tools they used and the kinds of people they asked for help. Interestingly, the 422 frames they used were not fixed; they evolved with the accumulation of 423 additional experiences and incorporation of others' opinions.

425 In the first frame, social media was perceived by some respondents as a 426 competitive game. Those employing this frame used competitive language and 
frequently compared their performance in establishing connections to their competitors.

I have a barometer of how well I'm doing on social media because I look at another business that's like mine. The owner has an advantage on me in terms of his staff and his location. But I'm absolutely wiping the floor with him as far as likes and followers are concerned. I get to see

The framing of social media as a competitive game led respondents to pay attention to the features of the platforms that reflected this metaphor (the numbers of followers and likes) and to focus on the quantity of new connections rather than the quality of their interactions. They talked about actively pitting themselves against those they saw as competitors. They indicated that competition required intensive effort, including work on social media out of office hours. They were focused on trying to accumulate the most followers, trying to be the first to comment on topical conversations in their industries and trying to create content that others would like and share. They hoped that such proactive efforts would create an impression that they were at the forefront of their industries and that this would attract the attention of potential collaborators. Their intensive efforts to compete and stay ahead of others on social media can be seen as a proactive approach to establishing new connections and fostering innovation, in which creating an impression of leading the pack is anticipated to lead to innovative opportunities.

The second frame used by the respondents was particularly apparent in the accounts of those who felt slightly unenthusiastic about social media use. Although they were aware that social media could give them access to new opportunities for innovation they felt the platforms held little personal appeal for them. They dealt with this dichotomy by framing social media as a box ticking exercise. 

Initially we were aware of it, but reluctant to use it because we knew how much time it would take. It was a box that needed ticking because new potential partners expected us to know about it, but we're not of a generation that wants to be constantly connected all the time so we did the bare minimum. (Owner-manager, design agency, Org 8)

These respondents who framed social media as a box ticking exercise talked about other preferred ways of meeting new innovation partners. There was an apparent tension in their accounts because they also recognized that it was possible to innovate using social media and they did not want to miss out. They used the box ticking frame as a way of dealing with the cognitive dissonance they associated with social media use. The metaphor suggests that they were following what they perceived to be the rules for developing new connections. They picked up these so-called rules as they observed and imitated the social media use of others. By jumping on the 'social media bandwagon' and following others they could access already existing templates and therefore regarded social media to be less effortful. Rather than attempting to formulate original and independent approaches to using the platforms they simply replicated what appeared to be popular practice. Thus, by taking what can be understood as a bandwagon approach to innovation they felt they were not missing out on the inherent opportunities of social media.

The third frame used by the respondents could be termed the informal frame. Although their ultimate goal was to make connections that would trigger innovation they understood social media to be a space where socialization would lead to business opportunities. When describing their approach they drew upon imagery that conjured a sense of an informal place where people were motivated to have fun and socialize.

I was very informal in my approach to it at first. I didn't take it particularly seriously. I treated it like a beach where I was dipping my toe in the water. I would go in gradually and just have fun with it. (Foundermanager, food \& drinks brand, Org 6) 
Many of the respondents using this frame were influenced by their own personal social media accounts wherein they interacted with friends and family and the content of most conversations typically had a familiar tone. They presumed that informality was the accepted social norm for interacting and building new connections on social media. Even though they were representing their

500 business they did not want to appear to overtly push a work related agenda in 501 their social media posts. Those who made use of this frame tried to make new connections by adopting a more casual style of communication. They were not deliberately trying to force new innovative partnerships to occur. As new social media connections were made they remained alert to emergent opportunities but did not go out of their way looking for new business. In this sense they were taking an emergent approach to innovation, by waiting for innovative circumstances to arise through socialization.

509 Overall, the three frames were suggestive of three distinct approaches to 510 establishing new connections and fostering innovation (i.e. proactive, 511 bandwagon and emergent approaches). The respondents used these frames 512 to facilitate a comprehensible interpretation of social media grounded in 513 everyday language. However, extant theory suggests that the mental effort of 514 framing alone is not sufficient to accomplish innovative outcomes. Individuals 515 also need to act upon their multiple framings. Goffman (1974:340) calls 516 attention to the necessity for socially constructed evidence (i.e. the various 517 social media frames in our case) to be fully mentally applied to a context if 518 innovative outcomes are to be achieved. In acting out the already invoked social 519 media frames our respondents turned to their wider experience, or what Swidler 520 (1986) refers to as cultural tools. According to Swidler (1986) these toolkits, 521 made up of skills, habits and styles, equip individuals to form diverse strategies 522 of action in everyday life. Figure 2 illustrates the relationship between two 523 respondent frames (informal and competitive game) and their manifestation as 524 action via specific tools. 


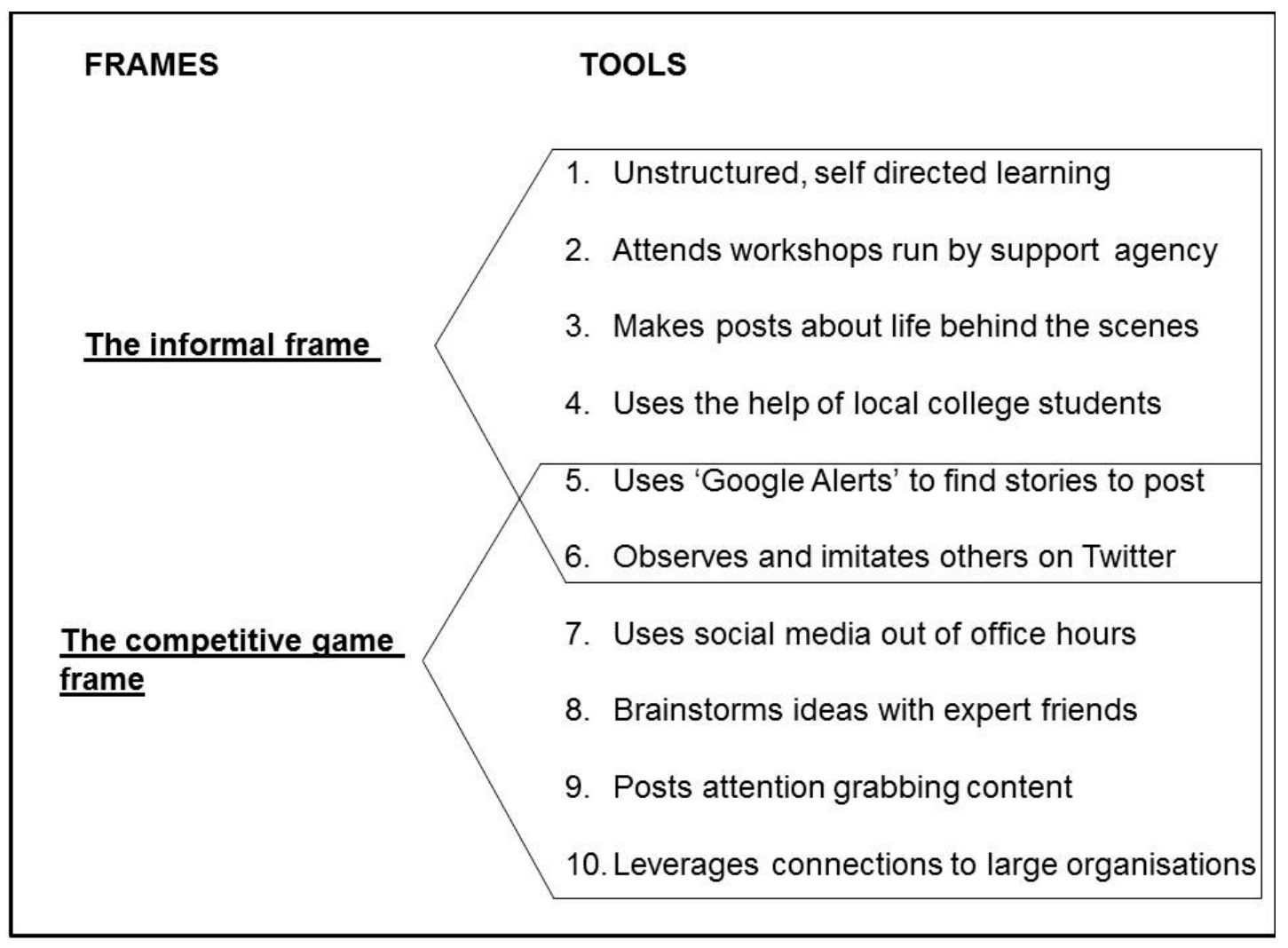

Figure 2: The formation of social media strategies of action

\section{Creating strategies of action}

530 Guided by their evolving understanding of social media, the respondents drew 531 on a wide variety of tools to aid them in achieving their innovative goals. In 532 many instances, they found that they had practical competencies that were 533 useful for attracting and interacting with new social media connections. They 534 talked about how these familiar skills helped them when they were unable to 535 introduce themselves as they would in a face-to-face setting. Most people I know are quite conscious of linking up to new businesses on social media because you just don't know who it is on the other end! My background is in marketing. I enjoy setting up a brand, coming up with the ideas, writing copy and doing the designs. So that's been useful for our social media work. I think we come across as a good business to be linked to thanks to our creative content. (Founder, Drinks brand, Org 5) 
Many respondents were concerned with creating a good first impression. The manager in the above quote focused on the impression created by the aesthetic appearance of his profile page and posts. He felt he was able to really appeal

548 to new connections by using his creative flair to present a well-considered style.

549 He explained that by using the skills he had established as a creative marketer

550 he was trying to compensate for the difficulties inherent in communicating with

551 others who were not physically present. Similarly, other respondents crafted 552 strategies drawing on their current skillsets. We needed to think about how to stand out and gain people's trust. I was looking at a lot of the waffle and jargon that other people were posting to make them look like experts. We decided to use plain, straight-talking English for our posts. That's how our profiles read. l'd attended a short course when the 'Plain English' campaign was around years ago, and I always thought it was the best way to communicate. (Founder, Design agency, Org 8)

Drawing on a style of communication that he had long been familiar with, this manager felt able to tackle the difficulties of establishing trust on social media. Despite the lack of flair associated with using simplified English, he felt that this style of post gave the impression that he had nothing to hide. Many respondents noted that they used styles of communication they were most familiar with and hoped that this would create a good impression and compensate for missing In other instances, respondents drew on their long established social

571 connections in the offline world for gaining insights into interacting and building 572 relationships on social media. annual marketing report. There's a big section in there on social media. 576 I always take on board suggestions from that report; I take them 

seriously and try them out to see what works for me. (Founder, Drinks brand, Org 7)

This manager needed to access technical knowledge that he didn't possess himself. He achieved this by turning to a friend who he trusted and whom he had gathered intelligence from on previous occasions. Some respondents explained that their connections to larger organizations helped them. They felt their difficulties in establishing new innovative relationships were caused by a lack of legitimacy linked to their small size. When they connected with large organizations on social media, they began to get noticed by others.

Forming partnerships with a major university and a Royal Society makes a huge difference. We've connected with them on social media as well and now rather than being a lone entity that no one's heard of people seem more willing to connect, they see me as being more established. I've now got access to a huge group of people on social media to collaborate with. (Founder, Chemistry Lab, Org 15)

This respondent's partnerships with the University and the Royal Society were already established, but he had not previously articulated his connection with them on his social media account. Once he did this, he received a much more positive response when initiating new contacts. He was also able to access and traverse the established networks of his partners, opening a much broader network of potential partners to communicate with.

In order to alleviate their uncertainty about how to approach social media use and build new connections some respondents sought advice from those they considered to be experts.

I was getting nowhere so I approached some of my programmers for advice. Now I'm making a real effort to generate conversations on social media and to do that you really have to join in quite frequently or you miss out on things. I commute in every morning, it takes about an hour on the train, and I take that hour to read and decide what I'm going to 
614 Having been advised of a new rule to follow (make posts often) the respondent

615 formed a new habit (posting three tweets on his daily commute) that girded his

616 efforts to find innovation opportunities on social media. His approach helped

617 him to generate ideas about new things to talk about and it made use of some 618 otherwise 'dead time' where he would be doing little else.

620 In summary, the above accounts show how respondents drew upon three 621 contrasting frames and a diverse set of practical tools to establish new 622 connections on social media. Drawing on this analysis, we discuss below the 623 potential of frames and cultural toolkits to establish new connections on social 624 media.

625

\section{DISCUSSION}

628 The analysis above unpacks the social processes underpinning the first stage 629 of social media innovation. Our specific focus on the attempts of individuals to 630 initiate new connections highlight the tremendous cognitive and practical efforts 631 required to achieve innovative outcomes via social media. When the usual 632 social cues associated with making new connections were found to be 633 ineffective on social media our respondents experienced a sense of uncertainty 634 about how to carry on. This uncertainty prompted them to frame social media 635 in what appeared to be three distinct approaches (i.e., proactive, bandwagon 636 and emergent) to making new connections and to innovation. In converting 637 frames into action, they drew upon what Swidler (1986) refers to as diverse 638 cultural toolkits of skills, habits and styles. The process is summarized in the 639 first box of Figure 3 below. In unpacking this important initial step we argue that 640 social media innovation is a complex cognitive achievement that relies upon 641 extensive psychological and social resources at each and every stage. 


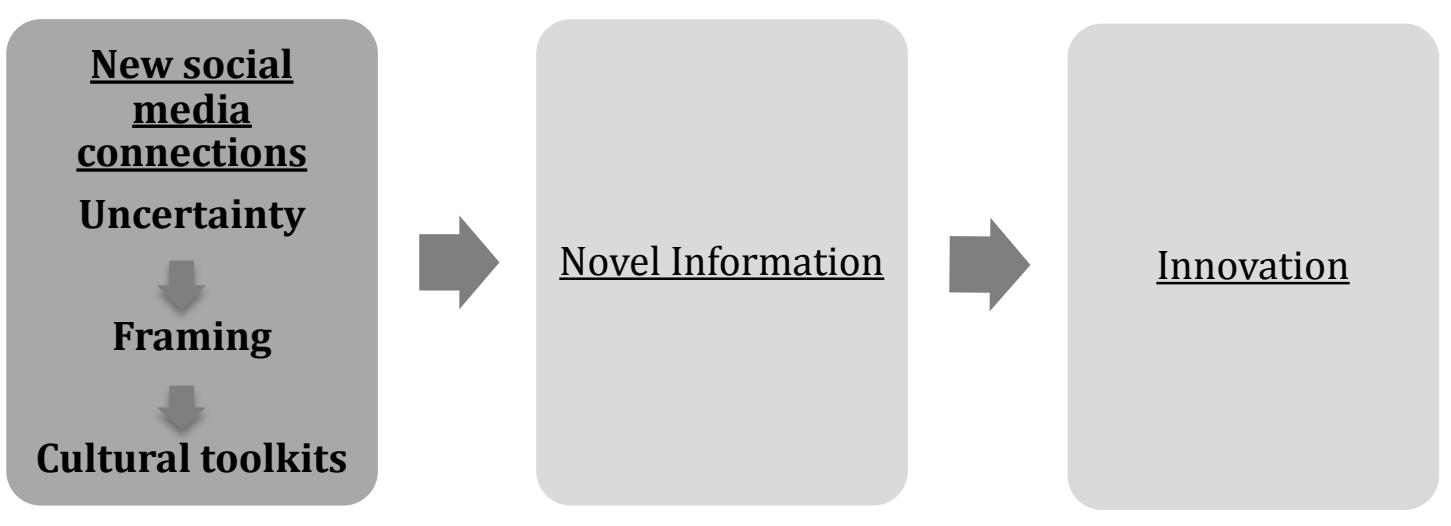

642

643 Figure 3: The impact of social media new connections on social media 644 innovation

646 Uncertainty and frames

648 The uncertainty experienced by the individuals in this study related to the 649 paucity of recognizable social cues on social media. Goffman (1979) dismissed 650 interactions mediated by technology as being "merely attenuated" and 651 "situation-like" (Goffman, 1979; Rettie, 2009; Richey et al., 2016). His assertion 652 was that interactions that rely upon technology do not provide sufficiently rich 653 social cues to constitute a full social interaction. Indeed, the literature suggests 654 that innovation requires such a complete social setting, rich in social cues (Rost, 655 2011) in order for collaboration and understanding to be achieved. These 656 assertions make our respondents' reaction to the uncertainty they experienced 657 particularly interesting. Rather than withdrawing from the socially unfamiliar and 658 sparse environment of social media, they invoked different frames in their 659 ultimate quest for innovative outcomes. This persistence may be partly 660 attributed to prevailing social norms. The widespread proliferation of social 661 media platforms may somewhat compel today's firms to stay active on social 662 media (Michelidou et al., 2011). Evidently, frames play an important part in this 663 process. In our case, framings and the associated mental simulations preceded 
664 action and provided proxies for the social cues that would normally be used to establish a strong context for interaction.

667 The frames for social media were invoked using everyday language that related 668 to three possible approaches to developing new connections and to innovation: 669 the proactive approach, the bandwagon approach and the emergent approach. 670 An important function of the frames was to create a perceptual link between 671 social media and these different ideas about innovation. While the lack of social 672 context initially hindered the launch of a potential innovation activity, frames 673 reignited the process since they were suggestive of ways of acting. In doing 674 this the frames effectively filled the void in contextual information left by missing 675 social cues. These findings indicate the important role frames play in reducing 676 the uncertainty associated with the initial stages of social media innovation. 677 Frames can serve as proxies for missing information, suggesting particular 678 approaches to innovation in the mind of individuals. By providing a mental 679 approximation of context they increase the individual's capacity for action.

680

Social media strategies of action

682

683 In acting upon framings of social media innovation, our respondents turned to 684 their established cultural toolkits (Swidler, 1986) of skills, habits and styles. In 685 this sense, frames and tools are mutually interdependent and may constitute 686 the fundamental components of social media strategies of action as depicted in Figure 2 earlier. Rather than attempting to learn how to use new tools for this unfamiliar activity (Molinksky, 2013) there was a clear tendency on the part of our respondents to turn to lines of action well-established in their offline world. Swidler (1986) suggests that individuals prefer making use of their practised tools in all situations since the cost of learning entirely new styles of behaviour is often perceived to be too steep. The use of familiar tools by our respondents

693 counterbalanced their feelings of uncertainty about social media innovation. 694 This grounding of actions in entrenched toolkits can be understood as an 695 attempt to make the unfamiliar, familiar. The tendency to turn to established 696 courses of action may seem counter-intuitive, given that the innovation process 697 is traditionally associated with attempts to break with convention (Mount \& 
Martinez, 2014; Leonardi, 2014). While later stages of the social media

699 innovation process may still rely upon integrating novel ways of thinking and 700 acting (Mount \& Martinez, 2014), our findings suggest that the initial step of 701 making new connections appears to depend upon established styles and 702 behaviours.

703

704 Implications for social media innovation

705

706 Social media have been regarded as providing favourable circumstances for 707 innovation, particularly by overcoming some of the difficulties usually 708 associated with making new connections and sharing novel information 709 (Leonardi, 2014, 2015; Mount \& Martinez, 2015). It has been suggested that 710 those that have traditionally struggled to access sufficient resources to 711 innovate, such as small and medium sized firms can particularly benefit from 712 these technologies (Harris et al., 2012). However, our findings imply that social 713 media is not necessarily an egalitarian space for innovation. From our 714 respondents' perspective, although it was theoretically possible to develop 715 different approaches to innovation using social media, in practice, access to a 716 pre-existing, broader cultural toolkit was required to turn their initial framings 717 into action. As we can tell from our data, these toolkits seemed to 718 simultaneously enable a sense of competence and familiarity as well as restrict 719 the set of available actions. This experience of our respondents suggest that 720 social positions and experiences may have a bigger say in the types of tools 721 that are familiar and accessible (Anthias, 2008; Swidler, 1986). In other words, 722 cultural tools are developed in everyday settings that social media cannot 723 entirely circumvent. We would therefore argue that social media appears to 724 reproduce social structures (Martinez Dy et al., 2016) in that those with access 725 to the broadest and the most sophisticated cultural toolkits are most likely to 726 succeed at social media innovation. Inevitably, before attempting to make 727 radical jumps in their social media use, individuals may spend considerable 728 time working with what they can access and know well (Swidler, 1986; Anthias, 729 2008). 
731 We would therefore argue that the ability of individuals to draw upon a rich array

732 of frames and cultural tools is an important antecedent of social media

733 innovation. This is because social media innovation is likely to involve the

734 initiation of new connections without the guidance of a full set of traditional

735 social cues. Previous studies have suggested that it is possible to develop a

736 sense of virtual co-presence (Huang et al., 2013) but these studies have

737 focused on communication within organizations. When using social media to

738 tuneinto the outside world uncertainty related to the absence of traditional social

739 cues (Goffman, 1959) was the major difficulty mentioned by our respondents.

740 Put differently, a sense of social context is necessary but likely to be missing

741 from the earliest stages of the innovation process due to the unavailability of

742 rich social cues. Our analysis suggests that in these early stages frames can

743 be used as proxies for missing social cues and thus may help better manage

744 the uncertainty. In this sense, they provide an approximation of context to guide

745 interactions with new connections during the initiation of the social media

746 innovation process.

748 Engagement with new connections has been recognized as increasingly 749 important to firms attempting to undertake open innovation activities (West \& 750 Bogers, 2013). The process of forging these new connections involves two 751 distinct groups. The first group are the internal contributors, or those 752 collaborating within the firm to initiate the innovation process. The second group 753 are external parties that the firm would like to involve in their innovative efforts. 754 Some attention has been given to motivating external parties to participate in 755 the early stages of innovation (Dahlander \& Piezunka, 2014). We contribute to 756 this strand of the innovation literature by unpacking the psychological micro757 processes underpinning the initiation of new social media connections. 758 Dahlander and Piezunka (2014) point out that much of the research in this 759 domain ignores or underplays the challenges of engaging with a broad array of 760 external contributors. Our study highlights the complex cognitive work required 761 to overcome the uncertainty associated with establishing new connections in 762 the initial stages of social media innovation. Additional work is needed to 763 provide a fuller picture of the role framings and interpretations have on the open 764 innovation process. For example, we have unpacked the role of frames at an 
765 individual level, but further research is needed to establish whether frames can

766 be used to create a shared context for innovation between those internal and

767 external to a firm.

768

769

\section{CONCLUDING REMARKS}

770

771 In this paper, we have argued that forming new social connections is a crucial

772 first step in the social media innovation process. There have been several

773 positive claims about the role of social media in facilitating new connections

774 and fostering innovation (Mount \& Martinez, 2014; Leonardi, 2014). While our

775 study does not contradict these claims, it shows that the initiation of new

776 connections on social media is not always straightforward. The process

777 involves complex cognitive effort as frames (Goffman, 1974) are used in lieu of

778 missing social cues. While frames help to overcome the uncertainty inherent in

779 the early stages of social media innovation they do not address the challenge

780 of accessing other types of resource characterized herein as cultural tools

781 (Swidler, 1986) that are necessary to turn framings in to action. Cultural tools

782 are not accessed via social media, but are nested in existing social structures.

783 Thus, those who are unable to access appropriate cultural tools may be less

784 able to act upon their intentions to innovate using social media.

785

786 This study places emphasis on the role of uncertainty in triggering the creative

787 use of frames and cultural tools. It is, of course, very likely that individuals will 788 become more familiar with social media over time. Our study has not captured 789 whether such a process of familiarization could reduce uncertainty about social 790 media technologies and thus reduce the creative use of frames and tools. 791 However, we would argue that the mediated nature of social media platforms 792 makes uncertainty an intrinsic feature of making new connections on social 793 media. While we anticipate that making social media connections to achieve 794 innovation will always involve a degree of uncertainty, more research is needed 795 to nuance this argument.

797 We also demonstrate how frames can be used as proxies for social cues in 798 order to help approximate a context for social media innovation. We 
acknowledge that the scope of our analysis is limited to the perceptions of individuals and the role of frames in initiating the social media innovation 801 process. In other words, the empirical material presented here relates to an 802 early step and does not relate to the later stages of the innovation process that 803 may rely even more heavily on communication and social cues. However, we 804 would argue that without this vital first step the social media innovation process 805 may not get started at all. Future research could focus on the potential and 806 relevance of frames in the later stages of social media innovation. For example, 807 it is worth investigating how co-communicants can work towards establishing a 808 shared sense of social context using frames and tools.

809

810 Finally, this study also provides some useful practical insights for managers 811 attempting to use social media to extend their social networks. By highlighting 812 the challenges inherent in establishing new useful connections on social media, 813 managers can prepare themselves by assessing their own 'cultural toolkits'. 814 The vocabulary offered in this paper offers a useful metaphor for managers as 815 they attempt to use frames and cultural tools as proxies for traditional social 816 cues available during face-to-face encounters.

\section{REFERENCES}

825 Anthias, F. 2008. Thinking through the lens of translocational positionality: An 826 intersectionality frame for understanding identity and belonging. Translocations: 827 Migration and Social Change 4(1): 5-20. Available at: 828 http://www.dcu.ie/imrstr/volume_4_issue_1/Nol_4_

829 Issue_1_Floya_Anthias.pdf (accessed 1 September 2016). 
830 Beech, N., MacPhail, S.A. \& Coupland, C. 2009. Anti-dialogic positioning in

831 change stories: bank robbers, saviours and peons, Organization, 16 (3), 832 pp.335-352.

833

834 Bjork, J. \& Magnusson, M. 2009. Where do good innovation ideas come from?

835 Exploring the influence of network connectivity on innovation idea quality.

836 Journal of product innovation management, 26 (6) pp. 662-670.

837

838 Cogburn, D.L. and Espinoza-Vasquez, F.K., 2011. From networked nominee to 839 networked nation: Examining the impact of Web 2.0 and social media on 840 political participation and civic engagement in the 2008 Obama campaign. 841 Journal of Political Marketing, 10(1-2), pp.189-213.

842

843 Coleman, J.S., 1988. Social capital in the creation of human capital. American 844 journal of sociology, pp.95-120.

845

846 Coleman, J. S., 1990. Foundations of Social Theory. Harvard University Press, 847 Cambridge (1990)

848

849 Cornelissen, J.P., Clarke, J.S. and Cienki, A., 2012. Sensegiving in 850 entrepreneurial contexts: The use of metaphors in speech and gesture to gain 851 and sustain support for novel business ventures. International Small Business 852 Journal, 30(3), pp.213-241.

853

854 Dahlander, L. \& Piezunka, H., 2014. Open to suggestions: How organizations 855 elicit suggestions through proactive and reactive attention. Research Policy, 85643 (2014) pp. 812-827.

857

858 French, A.M. \& Read, A. 2013. My mom's on Facebook: an evaluation of 859 information sharing depth in social networking. Behaviour and Information 860 Technology, 32 (10) pp.1049-1059.

862 Goffman, E., 1959. The Presentation of Self in Everyday Life, 2nd edn. 863 Harmondsworth: Penguin. 
865 Goffman, E., 1974. Frame analysis: An Essay on the Organization of 866 Experience. Harper and Row, New York.

868 Goffman, E., 1979. Gender Advertisements. New York: Harper and Row.

869

870 Goffman, E., 1981. Forms of Talk. Oxford: Blackwell.

871

872 Goffman, E., 1983. The interaction order: American Sociological Association,

8731982 presidential address. American Sociological Review, 48(1), pp.1-17.

874

875 Harris, L., Rae, A. and Misner, I., 2012. Punching above their weight: the

876 changing role of networking in SMEs. Journal of Small Business and

877 Enterprise Development, 19 (2), pp.335-351.

878

879

Huang, J., Baptista, J., \& Galliers, R.D., 2013. Reconceptualizing rhetorical 880 practices in organizations: The impact of social media on internal communications. Information and Management, 50, pp.112-124.

882

883 Kane, G.C., Alavi, M., Labianca, G., \& Borgatti, S. P., 2014. What's different 884 about social networks? A framework and research agenda, MIS Quarterly, 38 885 (1), pp.274-304.

886

Kaplan, A.M., \& Haenlein, M., 2010. Users of the World, unite! The challenges 888 889

890 Knowledge@Wharton, 2013. [online] How open innovation is solving some of 891 NASA's trickiest problems. [viewed on $1^{\text {st }}$ March, 2016] available from:

892 http://knowledge.wharton.upenn.edu/article/how-open-innovation-is-solving-

893 some-of-nasas-trickiest-problems/)

895 Koch, H., Leidner, D.E. \& Gonzalez, E.S., 2013. Digitally enabling social 896 networks: resolving IT-culture conflict. Information Systems Journal, 23 (6), 897 pp.501-523. 
899 Leonardi, P.M, 2011. Innovation blindness: culture, frames, and cross900 boundary problem construction in the development of new technology concepts. 901 Organization Science, 22(2) pp.347-369.

902

903 Leonardi, P.M., 2014. Social media, knowledge sharing, and innovation: 904 Toward a theory of communication visibility. Information systems research, 905 25(4), pp.796-816.

906

907 Martinez Dy, A., Marlow, S., \& Martin, L. 2016. A Web of opportunity or the 908 same old story? Women digital entrepreneurs and intersectionality theory. 909 Human Relations (forthcoming) DOI: 10.1177/0018726716650730

910

911 Mayasandra, R., Pan, S.L, \& Myers, M.D. 2006. Viewing information 912 technology outsourcing organisations through a postcolonial lens. In: Trauth,

913 E., Howcroft, D., Butler, T., Fitzgerald, B. \& De, Gross. J. Social inclusion, 914 societal and organisational implications for information systems, Berlin, 915 Springer.

916

917 Michaelidou, N., Siamagka, N., \& Chistodoulides, G., 2011. Usage barriers and 918 measurement of social media marketing: An exploratory investigation of B2B 919 brands. Industrial Marketing Management, 40 (7) pp.1153-1159.

920

921 Molinsky, A.L. 2013. The psychological process of cultural retooling. Academy 922 of Management Journal, 56 (3) pp.683-710.

924 Mount, M. and Martinez, M.G., 2014. Social Media: A tool for open innovation. 925 California Management Review, 56 (4), pp.124-143.

927 Ohly, S., Kase, R. \& Skerlavaj, M., 2010. Networks for generating and validating 928 ideas. Innovation: Management policy and practice, 12 (1) pp. 50-60.

929 Padgett, D.K. 1998. Qualitative Methods in Social Work Research: Challenges 930 and Rewards. Thousand Oaks, CA: Sage Publications. 
931 Ravishankar, M.N., 2013. Public ICT Innovations: a strategic ambiguity

932 perspective. Journal of Information Technology, 28 (4,) pp. 316-332.

933 Ravishankar, M.N., 2015. The realignment of offshoring frame disputes (OFD):

934 An ethnographic 'cultural' analysis. European Journal of Information Systems, $93524(3)$ pp.234-246.

936 Ravishankar, M.N., Cohen, L., \& El-Sawad, A. 2010. Examining resistance, 937 accommodation and the pursuit of aspiration in the Indian IT-BPO space: 938 reflections on two case studies. Industrial Relations Journal, 41(2), 154-167.

939 Rettie, R., 2009. Mobile Phone Communication: Extending Goffman to 940 mediated interaction. Sociology, 43 (3) pp.421-438.

941

942 Richey, M., Ravishankar, M.N. \& Coupland, C. (2016) Exploring situationally 943 inappropriate social media posts: An impression management perspective, 944 Information, Technology \& People, 29 (3) pp. 597-617.

945

946 Robert, C. \& Wilbanks, J.E., 2012. The wheel of humor: humor events and 947 affect in organizations. Human Relations, 65 (9) pp.1071-1099.

948

949 Rost, K., 2011. The strength of strong ties in the creation of innovation. 950 Research Policy, 40(4), pp.588-604.

951

952 Schein E., 1991. What is culture? In P. Frost, L. Moore, M. Louis, C. Lundberg, 953 and J. Martin (eds.), Reframing Organizational Culture. Newbury Park, CA: 954 Sage. pp. 243- 53.

955

956 Swidler, A., 1986. Culture in Action: Symbols and Strategies. American 957 Sociological Review, 51 (2) pp.273 - 286.

958

959 Treem, J.W. \& Leonardi, P.M., 2012. Social Media Use in Organizations:

960 Exploring the Affordances of Visibility, Editability, Persistence, and Association.

961 Communication Yearbook, 36 (2012) pp.143-189. 
963 Walsham, G. (1993), Interpreting information systems in organizations, Wiley, 964 Chichester.

965

966 Walther, J. B., 2007. Selective self-presentation in computer-mediated 967 communication: Hyperpersonal dimensions of technology,language, and 968 cognition. Computers in Human Behavior, 23 (5) pp.2528-2557

969

970 West, J. and Bogers, M., 2014. Leveraging external sources of innovation: a

971 review of research on open innovation. Journal of Product Innovation

972 Management, 31(4), pp.814-831.

973 